\title{
Dados abertos à brasileira: aspectos de uma cidadania denegada ${ }^{1}$
}

BRAZILIAN WAY OF OPEN DATA: ASPECTS OF A DENIED CITIZENSHIP

\section{Claudomilson Fernandes Braga}

Professor efetivo do Programa de Pós-Graduação em Comunicação da Universidade Federal de Goiás (UFG), coordenador do curso de graduação em Relações Públicas (PPGCOM/UFG).

E-mail: milsonprof@gmail.com

\section{Simone Antoniaci Tuzzo}

Professora efetiva do Programa de Pós-Graduação em Comunicação da Universidade Federal de Goiás (UFG), editora da revista Comunicação e Informação e coordenadora do curso de especialização em Assessoria de Comunicação e Marketing (PPGCOM/UFG).

E-mail: simonetuzzo@hotmail.com

Recebido em 12 de novembro de 2016. Aprovado em 3 de abril de 2017.

\section{Resumo}

Este estudo exploratório de cunho qualitativo netnográfico busca identificar e compreender o cenário da gestão de dados abertos no Brasil, dentro do conceito de comunicação de interesse público e cidadania. No ambiente investigado foram observadas três perspectivas: a produção sobre a temática no âmbito acadêmico; as ações de dados abertos na esfera do governo federal; as experiências dos governos estaduais mais o Distrito Federal, todas com o objetivo de identificar o que vem sendo produzido a título de transparência, política de dados abertos e sua efetiva operacionalização.

Palavras-chave: Dados abertos. Cidadania. Comunicação pública.

1 Pesquisa realizada no âmbito do Projeto de Pesquisa Ontologias para Dados Abertos, do Ministério da CulturaMinC - Subprojeto: Mapeamento de Experiências em Dados Abertos.

$48 \frac{\text { Comunicação \& Inovação, PPGCOM/USCS }}{\text { v. 18, n. } 37 \text { (48-65) maio-ago } 2017}$ 


\section{Abstract}

This exploratory qualitative netnographic study seeks to identify and understand the scenario of Open Data management in Brazil, within the concept of communication of public interest and citizenship. In the research environment, three perspectives were observed: the production in the academic field about the subject; the Open Data actions at the federal level; the experience of state governments plus the Federal District, all with the aim of identifying what has been produced regarding transparency, Open Data policy and its effective implementation.

Keywords: Open data. Citizenship. Public communication.

\section{Apresentação}

A ideia de estudar a gestão de dados abertos no Brasil tem fundamento na relação entre a comunicação e a cidadania, eixos que convergem para a compreensão dos interesses públicos, no sentido básico do binômio de oposição ao privado, ou seja, aquilo que deve ser aberto a todos, de interesse social, e não dentro de uma perspectiva de redefinição da ideia de público como distinção de grupos sociais, interesses que privilegiam públicos específicos. A política de dados abertos objetiva a publicar e disseminar informações públicas na web de forma a permitir que, a partir do conhecimento dos dados, os cidadãos possam refletir, aplicar e utilizar informações para o desenvolvimento de toda a sociedade.

De alguma forma, o fato de disponibilizar dados na web remete à reflexão sobre o caráter de coletividade e abrangência, de comunicação pública no sentido de algo para todos. Em uma sociedade onde pouco mais de $40 \%$ da população acessa a internet, a mesma tecnologia que publiciza, que dá visibilidade e transparência, também tem caráter de segregação, de distinção de públicos, de marcação periférica, em parte pela questão financeira, em parte pela questão do baixo nível intelectual de grande parte da sociedade formada por analfabetos funcionais, incapazes de compreender e interpretar o que leem.

Ainda assim, trata-se de uma nova postura, recente, e que deve ser observada como uma possibilidade de avanço. As ações de transparência governamental tiveram início em 2011, denominada de "Parceria para Governo Aberto" (OGP), do inglês Open Government Partnership, quando oito nações se uniram para selar uma aliança com esse objetivo. O Brasil, parceiro desses países, sancionou a Lei n ${ }^{\circ}$ 12.527/2011, a Lei de Acesso à Informação (BRASIL, 2011), que dispõe sobre os procedimentos a serem observados pela União, estados, Distrito Federal e municípios. 
Este trabalho busca identificar e compreender o cenário da gestão de dados abertos no Brasil, dentro do conceito de comunicação de interesse público e cidadania, cujo ambiente investigado observou três perspectivas: a produção sobre a temática no âmbito acadêmico; as experiências de dados abertos no âmbito do governo federal; as experiências dos governos estaduais mais o Distrito Federal; todas com o objetivo de identificar as experiências existentes no que se refere à política de dados abertos e sua efetiva aplicação.

Caracterizado como um estudo exploratório, a pesquisa observou dois polos investigativos: aquele construído e discutido no âmbito da comunidade acadêmica e outro pelo ângulo das organizações governamentais estaduais e federais.

O desenho metodológico de cunho qualitativo netnográfico é construído pela pesquisa bibliográfica, base para a fundamentação teórica que permitiu compreender a temática, e por outras três coletas, também de caráter bibliográfico, executadas no campo. Isso permitiu, a partir das análises inspiradas na perspectiva bardaniana de análise de conteúdo, compreender que os discursos sobre dados abertos estão intimamente ligados à transparência e ao governo aberto, sugerindo a necessidade de aprimoramento das plataformas de publicações de dados pelas organizações governamentais e a necessidade de discutir mais a fundo questões como o acesso, a leitura, a compreensão e a utilização dos dados por parte dos usuários. Dito de outra forma, a noção e as políticas de dados abertos no Brasil é frágil, distante do nível ideal de publicação de dados exigido pelas organizações de suporte à publicação de dados abertos e à própria legislação.

\section{Introdução}

No Brasil, o tema vem sendo cada vez mais discutido, principalmente depois de a Lei Complementar $n^{\circ} 131$ entrar em vigor em 27 de maio de 2009, conhecida como Lei da Transparência (BRASIL, 2012), uma espécie de continuação da Lei de Responsabilidade Fiscal, promulgada em 2000 (Lei Complementar nº 101, de 4 de maio de 2000), podendo ser considerado o primeiro passo rumo à disponibilização de dados abertos, mesmo que no primeiro momento a lei só objetivasse a prestação de contas e manutenção da integridade pública diante de um cenário de crise de imagem do governo federal por conta dos endividamentos que a esfera governamental passava naquele período (RAMINELLI, 2014). Mas alguns conceitos, como o estabelecimento de regras para divulgar informações, começaram a ser inseridos no âmbito governamental a partir desse período. 
No cenário internacional, o tema "dados abertos" vem sendo amplamente discutido desde 2007, quando alguns países como Reino Unido, Canadá e Estados Unidos começaram a publicar seus dados e consecutivamente mostraram ao mundo o processo de abertura de dados, atraindo vários países adeptos à ideia de disponibilizar abertamente dados à sociedade (LIRA, 2014).

Além da Open Government Partnership e da Lei de Acesso à Informação $\mathrm{n}^{\mathrm{o}} 12.527$ (BRASIL, [201-?]) - que tem o objetivo de regulamentar o direito constitucional de acesso dos cidadãos às informações públicas, exigindo que as organizações governamentais e organizações privadas sem fins lucrativos disponibilizem suas informações abertamente, conforme descrito acima -, em maio de 2016, a Presidência da República do Brasil publicou o Decreto do Executivo no 8.777/2016 (BRASIL, 2016) que institui a política de dados abertos do poder executivo federal, objetivando, entre outros itens, publicar dados contidos em bases de órgãos e entidades da administração pública federal direta, autárquica e fundacional sob a forma de dados abertos; aprimorar a cultura de transparência pública; franquear aos cidadãos o acesso, de forma aberta, os dados produzidos ou acumulados pelo Poder Executivo Federal, sobre os quais não recaia vedação expressa de acesso; facilitar o intercâmbio de dados entre órgãos e entidades da administração pública federal e as diferentes esferas da federação; compartilhar recursos de tecnologia da informação, de maneira a evitar a duplicidade de ações e o desperdício de recursos na disseminação de dados e informações; e oferecer serviços públicos digitais de forma integrada.

Atualmente, por conta da legislação, a ser discutida nesta pesquisa, todas as organizações governamentais publicam suas informações para a sociedade, porém, será que a difusão de dados no Brasil corresponde à forma ideal de publicar dados segundo a legislação? E o que dizem as instituições reguladoras do processo de abertura de dados? É sobre o que este trabalho se propõe a refletir: a realidade da situação da publicação de dados abertos no Brasil e como é discutida a política de dados abertos no âmbito da academia, de modo que, tanto as políticas como a discussão sobre o tema parecem ser em última análise uma inquietação sobre a própria cidadania, à medida que ter acesso à informação e poder, dentro dos padrões legais, e utilizar essas informações para melhor compreendê-las, são questões integrantes do processo de construção cidadã.

Nessa linha de raciocínio, de qual cidadão estamos falando? O cidadão conectado, pertencente ao mundo da tecnologia, ou o cidadão periférico? Ambos necessitam dos dados e ambos possuem o mesmo direito à informação. 


\section{Os dados abertos: compreendendo o conceito e sua relação com a cidadania}

Um dado independe de um contexto ou de uma interpretação. Contudo, dados isolados não exercem nenhuma importância, pois a relevância de um dado depende do contexto em que ele está inserido, e é esse contexto que determinará o valor do dado (AVILA, 2005).

Por isso é importante se inteirar do contexto em que o dado está inserido antes da sua manipulação, para que o trabalho com o dado possa contribuir para a construção de conhecimento e da cidadania.

Além de estar inserido em um contexto, para um dado fazer sentido, é necessário, de alguma forma, gerar novos produtos a partir da sua reutilização, e é nesse âmbito que se trabalha a ideia de dados abertos.

De acordo com a W3C Brasil, dados abertos são os dados distribuídos e compartilhados em formato aberto para que possam ser lidos por máquinas e pessoas, possibilitando a comunicação desses dados com outras fontes para serem reutilizados livremente pelos seus usuários, ou seja, é necessário que sejam dados interoperáveis (WORLD WEB CONSORTIUM BRASIL, 2011).

Segundo Sayão e Marcondes (2008), a interoperabilidade é a possibilidade da conversa entre diferentes sistemas de disponibilização de informações, ou seja, os dados devem ser integrados, reusados para que se tenha a cooperação entre dados, e consequentemente possam gerar informações mais completas.

Infelizmente um dos principais problemas encontrados em relação aos dados abertos são problemas no consumo, reutilização, identificação e interpretação por parte dos usuários. Segundo Lira (2014), um exemplo dessa realidade são os dados de instituições governamentais, que dificultam a compreensão e a interpretação das informações tanto por pessoas quanto por máquinas.

Para entender melhor o que são dados abertos e o que faz um dado aberto, a Open Knowledge Foundation apresenta as três diretrizes que regem os dados abertos, quais sejam: a disponibilidade e acesso; o reúso e a redistribuição; e a participação universal, que prevê a não discriminação contra áreas de atuação, pessoas ou grupos (OPEN DEFINITION, [201-?]).

O conceito de dados abertos tem como fundamentação a livre utilização das informações disponibilizadas pelos usuários. Este conceito é assegurado pelo governo no seu processo de abertura de dados aos cidadãos, garantido pelo inciso XIV, artigo $5^{\circ}$, da Constituição Federal Brasileira, e regularizada pela Lei de Acesso à Informação (LAI). 
Visando essas novas formas de gestão, especialmente de aproximação com anseios da sociedade, surge a ideia de "governo aberto", que junto à ideia de dados abertos, segundo Dutra e Lopes (2013), "estão sendo vistos como uma possibilidade de geração de valor econômico, visto que permite a criação de mais empregos e empresas quando da agregação de valor aos dados abertos".

Promover a cidadania e a transparência é uma ação de fundamental importância para a manutenção da imagem de um governo, e nesse sentido surgiu o conceito de "governo aberto", disponibilizando dados e informações transparentes sobre o governo, contribuindo para a participação da sociedade nas ações governamentais e, consequentemente, para que a sociedade colabore com a administração pública e crie soluções para problemas sociais a partir dos dados disponibilizados (BANDEIRA et al., 2014).

O termo "governo aberto" significa a gestão governamental mais transparente, com dados e informações de fácil acesso aos usuários. Assim, a população é efetivamente inserida no processo de tomada de decisão, participando das escolhas, metas e caminhos a serem seguidos ao longo do desenvolvimento de políticas públicas.

Lembrando que, antes da transparência, "governo aberto" englobava a prestação de contas, fato que fica mais evidente no Brasil, onde a Lei de Responsabilidade Fiscal entrou em vigor bem antes da Lei de Acesso à Informação.

O objetivo dos dados abertos governamentais não é oferecer dados e informações prontas para o uso, mas possibilitar o acesso dos usuários à base de dados do governo para possibilitar a participação da sociedade nas ações do governo, e só assim os dados abertos governamentais atingirão seus objetivos.

A importância está em pensar que disponibilizar dados, e apenas isso é, no mínimo, insignificante. A noção de dados abertos ultrapassa o caráter de publicização. É permitir que dados possam ser interpretados, manuseados pelos cidadãos, no sentido de oferecer em um processo dialógico, retroinformações aos governantes, para que possam contribuir com a gestão democrática da comunidade, da cidade, do estado, do país. Assim se firma a relação entre os dados e a construção da cidadania.

Dessa forma, o direito à informação adequada deve ser agregado ao direito à educação, para que se possa interpretá-la, caso contrário todo o processo seria comprometido, em uma sociedade de analfabetos funcionais, e os dados acabam por auxiliar alguns privilegiados, e não toda a sociedade.

Discutimos assim a própria questão da coisa pública que fica, nessa circunstância, relativa à distinção de públicos, e não ao todo. Aqui o público não se opõe ao privado, mas sim legitima a existência de públicos distintos que podem ou não ter acesso à informação a partir de sua condição social. 


\section{Amostra, métodos e procedimentos: aspectos gerais da pesquisa de campo}

Este trabalho foi realizado a partir das atividades no Projeto Dados Abertos e Ontologias para a Gestão Cultural do Ministério da Cultura, dentro do subprojeto Mapeamento de Experiências, no período de agosto de 2015 a agosto de 2016, tendo sido financiado pelo Ministério da Cultura.

A pesquisa foi dividida em três etapas: na primeira, uma pesquisa por dados abertos na perspectiva da comunidade acadêmica; na segunda, buscou-se identificar se órgãos do Governo Federal e suas secretarias com status de ministério tinham como prática de gestão a abertura de dados; e uma terceira coleta, voltada para os governos estaduais e empresas privadas que publicam seus dados abertamente no Brasil.

Optou-se por um método qualitativo para entender um fenômeno específico com mais profundidade. Segundo Tuzzo e Braga (2016), a abordagem qualitativa enfatiza a qualidade e a profundidade de dados e descobertas a partir de fenômenos, pois o foco está na interpretação, valorizando o processo e o seu significado. A pesquisa qualitativa é analítica, explicativa, ou seja, ela é regida pelos dados que gerarão conclusões e reflexões, baseados na complexidade da sociedade onde a pesquisa foi gerada.

A escolha da pesquisa qualitativa se deu pela natureza investigativa desse trabalho, que tem como objetivos: entender como a comunidade acadêmica tem observado, retratado e discutido a noção de dados abertos na América Latina, Estados Unidos e Europa; e compreender como as organizações governamentais e privadas brasileiras publicam seus dados e quais dados são publicados no âmbito estadual e federal, à medida que essa postura governamental indicam de certo modo o lugar da cidadania neste processo.

Para tal, foram realizadas pesquisas netnográficas na rede mundial de computadores. Segundo Hine (2000), as pesquisas netnográficas despontam como uma tendência como método de investigação nos ambientes virtuais em uma sociedade e um momento histórico em que diversas soluções metodológicas se apresentam para estudo do ciberespaço e seus desdobramentos. Porém, ainda não está muito claro como utilizar, em sua plenitude, essas metodologias que foram herdadas das ciências tradicionais, bem como quais as brechas existentes.

A netnografia pode ser utilizada de diferentes maneiras, porém, foi adotada neste trabalho como ferramenta exploratória para então estudar como se procede a gestão de dados abertos no Brasil.

Os resultados das três coletas foram interpretados a partir da perspectiva da análise de conteúdo de inspiração bardaniana e teve como suporte de análise o Iramuteq, 
software gratuito e desenvolvido sob a lógica open source, licenciado por GNU GPL (v2), sendo ancorado em um ambiente estatístico do software R e na linguagem Python.

Diferentemente de outras técnicas, como a análise de discurso, a análise de conteúdo é sempre feita a partir da mensagem e tem por finalidade a produção de inferências, ou seja, é feita uma proposição em razão dessa inferência, de onde se deriva uma proposição e outras proposições já aceitas como verdade.

Como explica Bardin (1977), a análise de conteúdo é um conjunto de técnicas de análise das comunicações que visa obter procedimentos sistemáticos e objetivos de descrição do conteúdo das mensagens, envolvendo tanto a linguística tradicional como a interpretação dos sentidos das palavras, ou seja, indicadores que permitam a inferência de conhecimentos relativos às condições de produção e recepção dessas mensagens. Constitui-se, assim, como um método de tratamento da informação contida nas mensagens que abarca tanto os conteúdos quanto as figuras de linguagem, as entrelinhas e as manifestações do autor.

Esse programa informático viabiliza diferentes tipos de análise de dados textuais, desde aquelas bem simples, como a lexicografia básica (cálculo de frequência de palavras), até as multivariadas (classificação hierárquica descendente, análises de similitude). Ele organiza a distribuição do vocabulário de forma facilmente compreensível e visualmente clara (análise de similitude e nuvem de palavras) (CAMARGO; JUSTO, 2013).

\section{Etapa 1: Pesquisa sobre dados abertos na perspectiva da Academia}

Com o objetivo de entender como a comunidade acadêmica tem observado, retratado e discutido a noção de dados abertos na América Latina, Estados Unidos e Europa, os trabalhos selecionados que serviram como base foram localizados dentro do recorte cronológico de 2006 a 2016, a partir das palavras-chave: dados abertos; Open Data; Datos Abiertos; Gobierno Abierto; Dados governamentais abertos; Transparência; Governo Aberto, dentro dos indexadores de trabalhos acadêmicos: Scientific Electronic Library Online (SciELO) e, de modo aleatório por conveniência, os repositórios da Universidade de São Paulo (USP), Universidade de Brasília (UnB), Universidade Federal de Minas Gerais (UFMG), Universidade Federal de Pernambuco (UFPE), Universidade Federal da Paraíba (UFPB) e Banco de Teses e Dissertações da Coordenação de Aperfeiçoamento de Pessoal de Nível Superior (Capes).

Os critérios de seleção adotados foram as palavras-chave dados abertos (e suas variações) e o conteúdo dos trabalhos disponíveis nos repositórios, observando os trabalhos que continham as melhores práticas e metodologias de dados abertos. Assim, foram 
selecionados 55 trabalhos, entre artigos, monografias, dissertações e teses, sendo 4 da Capes, 5 da UFPB, 7 da UnB, 4 da UFMG, 6 da UFPE, 8 da USP e 20 da SciELO.

As análises foram feitas com o software Iramuteq (Interface de R pour les Analyses Multidimensionelles de textes e de Questionaires).

O corpus de análise foi preparado em uma tabela no Microsoft Excel, em que cada linha da tabela correspondia ao resumo de cada texto selecionado, que construíram as palavras utilizadas no software Iramuteq. Essas palavras foram submetidas ao processo de tratamento no software, permitindo a análise de similitude do corpus e o quadro de quatro casas construídas pelo software Iramuteq a partir da teoria dos grafos, que, através do número de ocorrências e grau de conexão entre as palavras, auxilia a identificação da estrutura da representação. Por fim, um quadro foi criado, que é uma nuvem de palavras, uma análise lexical mais simples, em que as palavras são organizadas graficamente, baseadas na frequência de aparição nos textos (RAGON, 2015).

A leitura do quadro de quatro casas é explicada por Santos et al. (2013):

O quadrante superior esquerdo apresenta as palavras mais frequentes e mais prontamente evocadas, o que indica que provavelmente fazem parte do núcleo central da representação. No quadrante inferior esquerdo aparecem os termos com frequência menor, mas prontamente evocados, e no superior direito, os muitos frequentes, mas não tão prontamente citados. Esses dois quadrantes indicam as palavras que possivelmente pertencem ao sistema periférico das representações e estão mais próximos ao núcleo central. Por fim, o quadrante inferior direito indica os termos que foram pouco frequentes e menos prontamente evocados, indicando a periferia distante. (p. 458)

Já a análise de similitude, também fundamentada na teoria dos grafos (MARCHAND; RATINAUD, 2012), é um método frequentemente utilizado por pesquisadores das representações sociais, pois identifica as coerências e conexões entre as palavras em seu resultado.

Esse método de análise objetiva detectar o grau de conexão entre elementos identificados nos trabalhos localizados como participantes da representação social analisada pela pesquisa.

\section{Discussão dos resultados - primeira etapa}

A partir da análise do quadro de similitude, procurou-se perceber o que diz o corpus, e dentro dessa perspectiva, a essência da publicação dos dados abertos.

O quadro de similitude, também denominado de "árvore máxima de similitude" (Figura 1), indica uma visão mais aprofundada sobre a forma com que o corpus discute 
a noção de dados abertos. Observamos que as palavras de maior representatividade no corpus são: transparência, governamental e governo.

A noção de dados está diretamente ligada à transparência, mostrando que, quando se discute abertura de dados, sempre associam o discurso à transparência. A palavra "abertos" se relaciona diretamente com o governo, mostrando que a abertura de dados está ligada a ele.

Porém, o que mais chamou a atenção foi a periferia das palavras "usar" e "entender" que aparecem ligadas à palavra "aberto", mostrando que no contexto atual, na abertura dos dados, o uso e o entendimento das informações disponibilizadas não são prioridade.

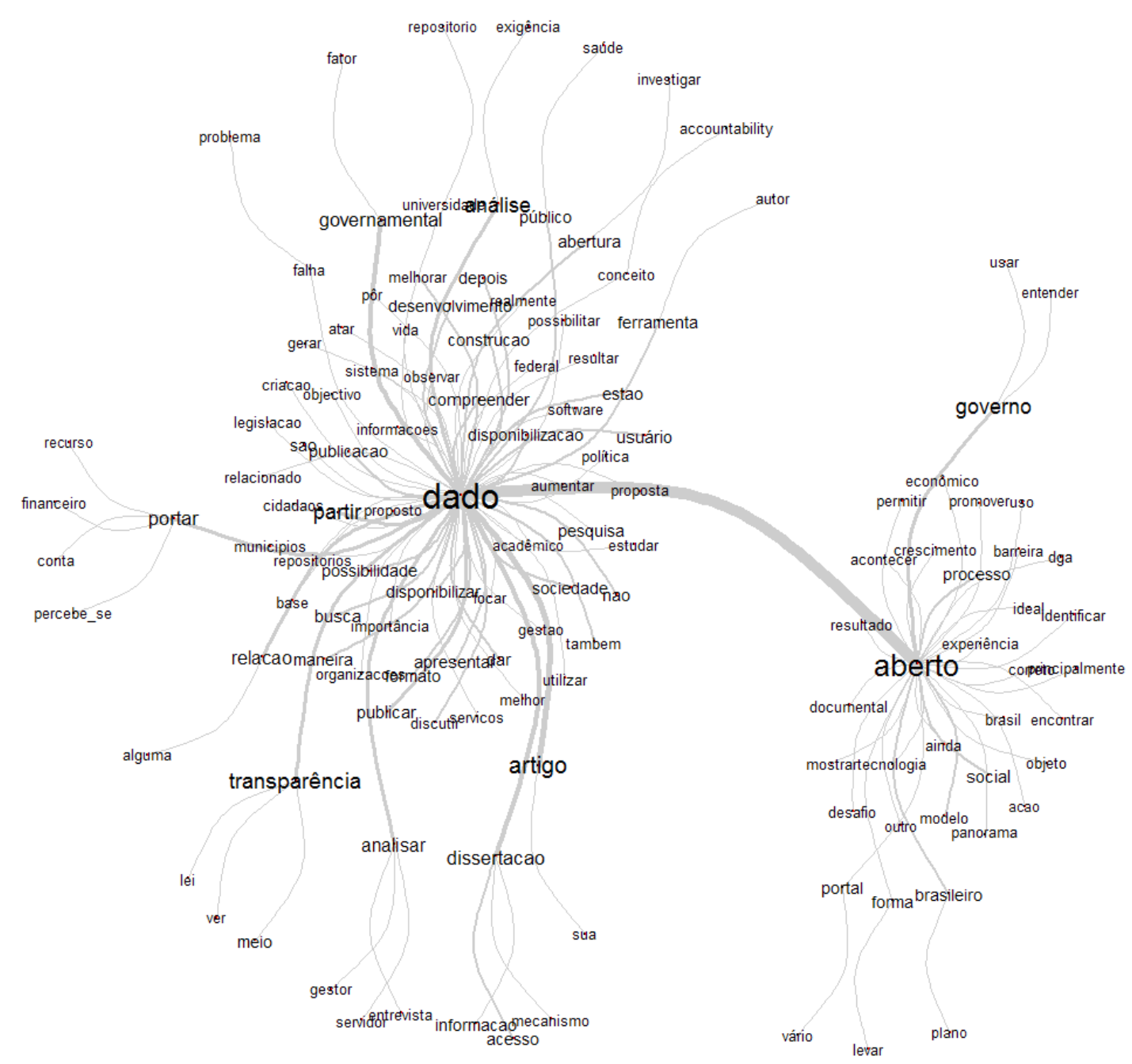

Figura 1. Quadro de similitude

Fonte: Elaboração dos autores. 
Quando olhamos as duas palavras chave da análise do software juntas, "dados abertos" são associados à "transparência dos dados do governo", vistos até mesmo como elementos similares, e compreendemos também que a essência do dado aberto não é a publicação, mas a noção de ler, ver, analisar, informar e usar por parte dos usuários, para promover ações que auxiliem a sociedade.

\section{Ełapa 2: pesquisa em órgãos do governo federal e empresas privadas que publicam seus dados}

Averiguamos quais órgãos do governo federal e empresas privadas brasileiras publicam seus dados abertamente. Optamos pelo método qualitativo netnográfico como meio de investigação para responder às inquietações do problema de pesquisa. A análise dos resultados foi baseada na análise de conteúdo, por ser a metodologia mais adequada ao que é proposto por se desenvolver utilizando a comunicação como ponto de partida.

A pesquisa foi dividida em três ações: averiguar quais organizações publicam seus dados abertamente; investigar cada órgão com o objetivo de descobrir qual o tipo e de que forma os dados são publicados; por fim, a acessibilidade do dado publicado em cada órgão explorado.

Escolhemos o ambiente web para esta pesquisa porque a publicação de dados na web é uma das premissas que regem os dados abertos, tanto conceitualmente quanto legalmente falando. Segundo David Eaves ${ }^{2}$, existem três "leis" que regem os dados abertos, e dentro delas, está previsto que um dado, para existir, necessariamente precisa ser indexado na web; o formato de publicação de dados precisa ser disponibilizado em formato compreensível por máquinas; e para o dado ser útil, deve conter dispositivos que permitam sua replicação.

Desse modo, foram explorados os portais de: todos os ministérios do governo federal; quatro secretarias federais ligadas à Presidência da República (Aviação Civil da Presidência da República, Comunicação Social da Presidência da República, Portos da Presidência da República e Secretaria-Geral da Presidência da República); sete órgãos federais (Câmara dos Deputados, Casa Civil da Presidência da República, Controladoria Geral da União, Vice-Presidência da República, Senado Federal, Advocacia Geral da União e Superior Tribunal de Justiça); além de oito empresas do

2 David Eaves: especialista em políticas públicas e ativista dos dados abertos. Autor de vários textos sobre inovação aberta, a ordem pública, a renovação do setor de serviços públicos, de código aberto e sistemas de rede (BRASIL, [201-?]).

$58 \frac{\text { Comunicação \& Inovação, PPGCOM/USCS }}{\text { v. 18, n. 37 (48-65) maio-ago } 2017}$ 
governo federal (Banco do Brasil, Correios, Caixa Econômica Federal, BNDES, Banco Central, Telebras, Transpetro e Petrobras).

\section{Discussão dos resultados - segunda etapa}

Sabemos que as empresas do setor privado não publicam seus dados abertamente por conta da concorrência e por segurança, com o objetivo de proteger informações. A partir dos dados obtidos nesta pesquisa, percebe-se que isso também ocorre em organizações federais governamentais de capital misto, como a Petrobras, a Caixa Econômica Federal e o Banco do Brasil, com a ressalva de algumas informações relacionadas à prestação de contas que podem ser obtidas mediante solicitação no portal e-Sic (Sistema eletrônico do serviço de informação ao cidadão).

Os órgãos do governo federal publicam livre e abertamente dados relacionados a gastos, despesas, receitas e orçamentos, indicando que a publicação de dados nesses órgãos acontece primeiramente por conta das legislações que regem o Governo Aberto (Lei de Acesso à Informação, Lei de Responsabilidade Fiscal), e depois para a reutilização, levando em conta que, além de informações limitadas, a maioria dos dados publicados não é manipulável ou apresenta limitações em relação ao nível de abertura, ou seja, não apresenta formatos que possam ser lidos por máquinas.

Outro aspecto que deve ser destacado é o fato de que não existe uma padronização da maneira como os dados são publicados pelos órgãos investigados, o que prejudica a experiência do usuário nos portais. Também foi encontrada uma grande diversidade de formatos de publicação, que vão de PDF (maioria) a CSV, porém, percebe-se que a maioria dos formatos de publicação de dados encontrados apresenta algum tipo de limitação em relação ao seu nível de abertura.

\section{Etapa 3: pesquisa por possíveis órgãos dos governos estaduais brasileiros que publicam seus dados}

Buscamos investigar também no ambiente web quais estados brasileiros publicam seus dados abertamente à sociedade. Igualmente à etapa anterior, optou-se pelo método qualitativo, utilizando o método netnográfico como meio de investigação para responder o problema de pesquisa.

Como metodologia de análise dos resultados, também foi utilizada a análise de conteúdo, por ser método que traria melhores resultados para a pesquisa. Assim como o governo federal, a Lei de Acesso à Informação também abrange os governos estaduais brasileiros, estabelecendo que, em relação à publicação de dados, eles têm a mesma 
responsabilidade perante a Lei: oferecer ao cidadão um padrão de acesso, que facilite a localização e obtenção das informações e se torne para ele, também, uma referência em transparência pública (CGU, 2011).

Desse modo foram investigados os 27 estados brasileiros mais o Distrito Federal no ambiente web, com o objetivo de averiguar como esses estados publicam seus dados abertos, qual o tipo de informação e qual o panorama de acessibilidade do usuário nos portais explorados.

\section{Discussão dos resultados - terceira etapa}

A partir do estudo exploratório, encontrou-se uma situação bastante parecida com a realidade encontrada na etapa 2 da pesquisa pelos possíveis órgãos do Governo Federal que publicam seus dados.

O primeiro aspecto de destaque é o fato de todos os portais explorados apresentarem falhas na disponibilização dos seus dados, sobretudo problemas relacionados ao formato, onde a grande maioria apresenta baixos níveis de abertura, pois, segundo a Open Knowledge Brasil, existe uma lógica de qualificação em relação às publicações de dados abertos desenvolvidas a partir das ideias de Tim Berners-Lee, o inventor da web, que sugeriu um esquema de 5 estrelas para publicação de dados abertos (Figura 2).

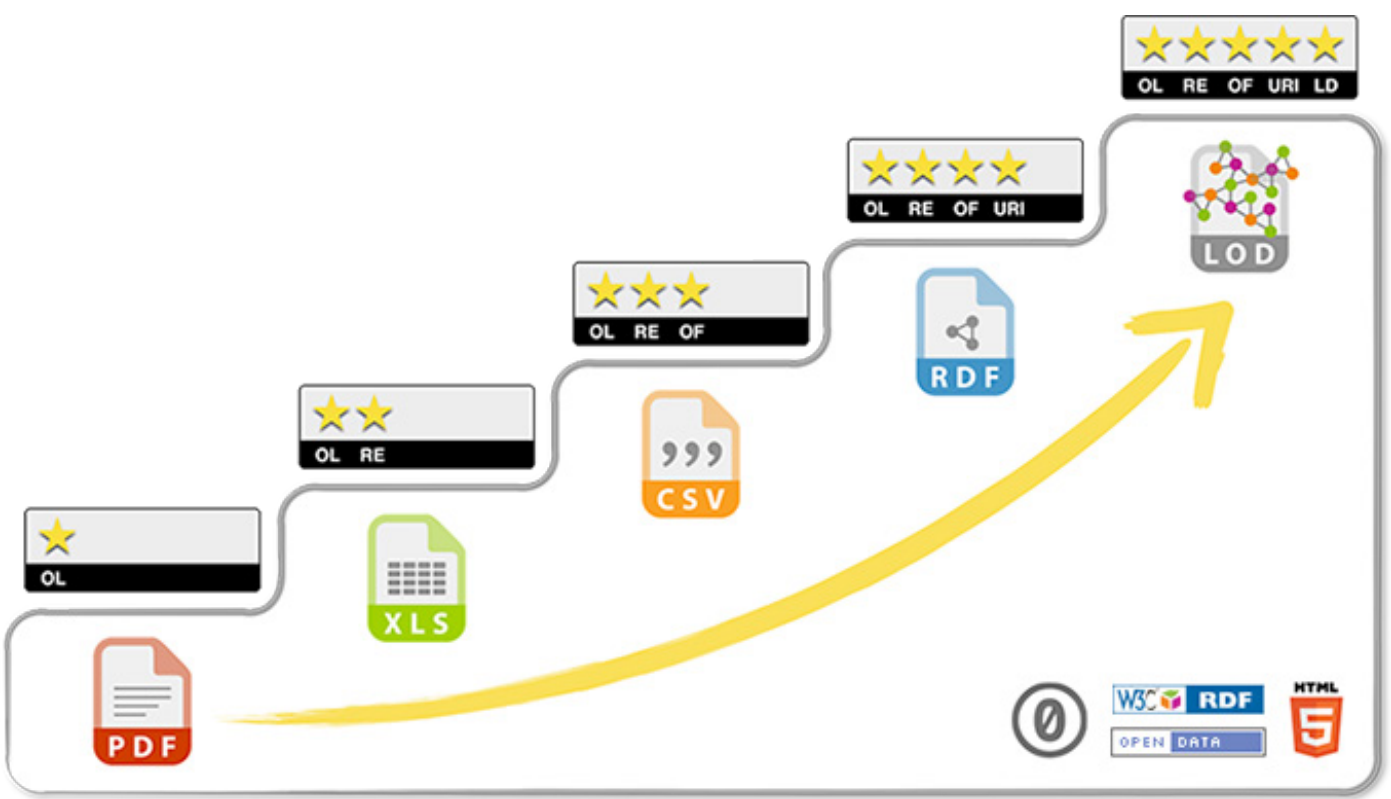

Figura 2. Star deployment scheme for Open Data

Fonte: 5* Open data ([201-?])

$60 \frac{\text { Comunicação \& Inovação, PPGCOM/USCS }}{\text { v. 18, n. } 37 \text { (48-65) maio-ago } 2017}$ 
Segundo essa proposta de Tim B-Lee (s.d.), quanto mais estrelas o formato tem em sua classificação, mais aberto ele é, mais possibilidades de manipulação e mais maturidade tem o dado.

Assim, como grande parte dos dados encontrados nos portais explorados varia entre PDF e CSV, é perceptível que o formato em que os dados estão sendo publicados nesses portais não são os ideais, principalmente o formato PDF, quando se pensa em manipulação e reutilização de dados.

Os dados encontrados se limitam, na grande maioria, em informações sobre receitas, despesas, servidores, contratos, licitações, convênios, balanços, educação, saúde, repasse a municípios e planejamentos. Observa-se a partir deste fato que a ideia de publicação de dados ainda está relacionada à prestação de contas. Esse fato se repete na maioria dos estados que seguem uma constância em relação ao modelo e aos conteúdos publicados.

Isso também nos leva a observar que da mesma forma em que é percebida nos portais do governo federal, a publicação de dados abertos no Brasil acontece somente porque é uma exigência da lei; o fato da reutilização desses dados pela sociedade fica em segundo plano.

Poucos são os estados que desvinculam a ideia de "transparência" de "dados abertos". Apenas Minas Gerais, São Paulo e Rio Grande do Sul fazem essa diferenciação, disponibilizando um portal voltado para a transparência e um portal voltado para a disponibilização de dados em formato aberto para serem reutilizados pelos usuários.

Em relação à acessibilidade, foram observadas algumas falhas em relação à disposição das informações nos portais que dificultam a navegabilidade do usuário, que pode ter problemas para encontrar as informações desejadas.

Em relação às variáveis "número de informações disponíveis", "processos burocráticos para se ter acesso às informações" e "formatos de disponibilização", a realidade dos portais dos governos estaduais está um passo à frente dos portais dos órgãos do governo federal. Mesmo com as falhas observadas, percebe-se que os estados brasileiros disponibilizam mais informações aos usuários em seus portais do que o governo federal.

\section{Algumas considerações}

A noção de dados abertos vai muito além dos conceitos de transparência. Transparência é o empenho das organizações com a prestação de contas (PINHO, 2008). Já o conceito de dado aberto é mais amplo que isso, além da transparência, o dado aberto contribui para com a sociedade como base de serviços inovadores, aprimora a qualidade 
dos dados governamentais e viabiliza novos negócios a partir da reutilização desse dado3 . Porém, percebe-se que a noção de que são dois conceitos distintos ainda não foi compreendida pelas instituições que publicam seus dados abertamente.

Esta percepção é identificada nas três coletas da pesquisa realizada, cujo objetivo foi identificar e compreender a realidade da publicação de dados abertos no Brasil. Ainda se tem no conceito de transparência e no conceito de dados abertos um tratamento similar, como se tratassem da mesma coisa e isso é identificado tanto por parte da comunidade acadêmica como pelos portais de disponibilização de dados governamentais em âmbito estadual e federal.

Em razão dessa não ocorrer essa distinção entre transparência e dados abertos são ocasionados fatos que chama bastante atenção nos resultados da pesquisa. A publicação de dados é vista como prestação de contas pelas organizações públicas analisadas, os pilares dos dados abertos (como a possibilidade da interoperabilidade e o fácil acesso à informação e usabilidade) infelizmente estão em segundo plano no processo de gestão de dados abertos públicos brasileiros.

E a solução para esses problemas? Percebe-se que os órgãos governamentais que publicam seus dados seguem um modelo de publicação que ainda não é ideal, apesar de recentemente o Ministério do Planejamento e Orçamento ter publicado manual para elaboração de Plano de Dados Abertos. Entretanto esse cenário indica apenas um avanço, longe da realidade de outros países como os Estados Unidos e a Inglaterra, onde a política de dados abertos é uma realidade.

Este panorama ainda em construção aponta que a noção de cidadania e democracia em relação aos dados abertos parece distante. Grosso modo, a abertura de dados no Brasil de longe não se aproxima da real compreensão desta atribuição do Estado brasileiro em todas as suas esferas e, dessa forma, compromete a noção de cidadania que, ainda que inspirada na perspectiva marshalliana (1967), se transformou com o advento das tecnologias da informação e da comunicação (TICs), superando a tríade de direitos políticos, civis e sociais e agregando novas categorias, como a informação, por exemplo. Neste sentido estamos ainda no início de uma busca.

Assim, falar de dados abertos é seguramente falar de cidadania. Impossível uma cidadania plena para alguém que não participa do processo de gestão da sua própria existência enquanto cidadão. Seria quase possível afirmar que ao cidadão brasileiro cabe apenas o lugar do espectador, impávido, imóvel e um desejante eterno daquilo que somente vê nas mãos de alguns afortunados. Um contrassenso em se tratando de cidadania.

3 Portal brasileiro de dados abertos. Disponível em: <http://dados.gov.br/dados-abertos/>.

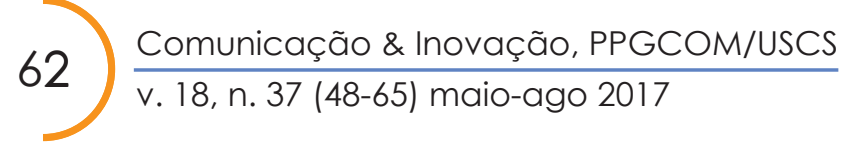




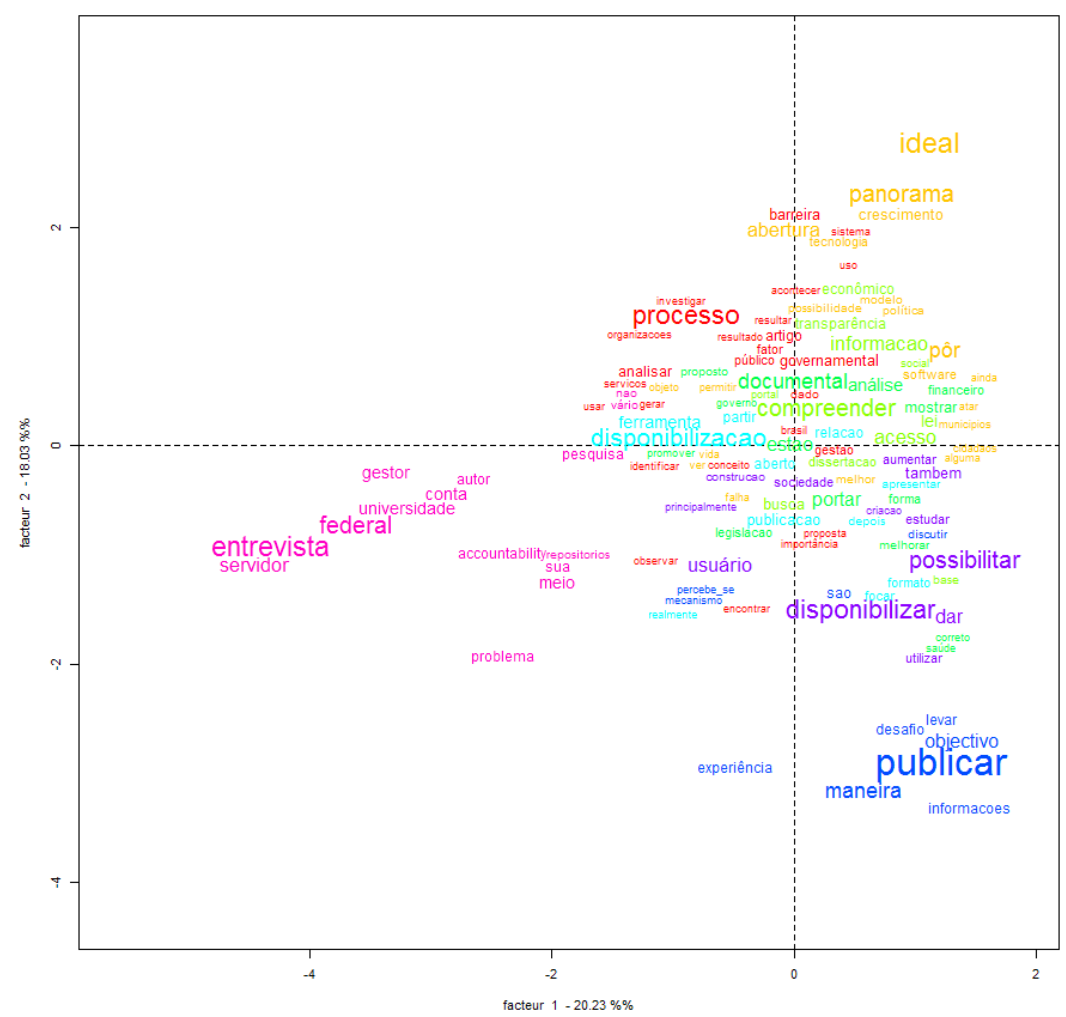

Figura 3. Quadrante de Quatro Casas

Fonte: Elaboração dos autores

O quadrante de quatro casas resultantes da coleta nas bases indexadas indica de modo claro o quanto o discurso da academia tem refletido a prática dos órgãos governamentais e de certo modo as suas ações. A academia também discute dados abertos como se se tratasse de transparência. No quadrante superior direito, lugar do principal discurso, a expressão dados abertos nem se apresenta. Só no quadrante inferior direito, já no discurso periférico, é que noções preliminares surgem: “disponibilizar”, "publicar”, "possibilitar", entretanto, tudo incipiente.

Se na academia, lugar privilegiado das discussões, da construção do conhecimento, os dados abertos, enquanto possibilidade cidadã, ainda são construídos de modo tímido, o que dizer das instâncias de poder em que a cidadania deveria se concretizar em ações?

Ao usuário coube o lugar mais distante das periferias: o quadrante inferior esquerdo, e nesse sentido, apesar de pesquisas terem, ao longo do tempo, se debruçado sobre o viés da cidadania enquanto construto baseado nos direitos clássicos, ainda é incipiente a perspectiva de que a cidadania é não apenas um status, mas, sobretudo, uma condição, um ser, e não um ente, um estado de espírito. Não ter a informação aberta, livre de arranjos informáticos que iniba seu manuseio, é na verdade inibir a própria 
cidadania, ou no mínimo reduzi-la a uma condição medíocre, mediana, em processo de eterna construção, longe de ser uma realidade vivida. Trata-se na verdade da negação de uma cidadania. Uma cidadania denegada.

\section{Referências}

5* OPEN DATA. 5* Open Data. [201-?]. Disponível em: <http://5stardata.info/en/>. Acesso em: 27 jun. 2017.

AVILA, T. J. T. Portais corporativos: uma ferramenta estratégica de apoio à gestão do conhecimento - um estudo de caso no Detran/AL.77 f. 2003. Monografia (Graduação em Ciência da Computação) Departamento de Tecnologia da Informação da Universidade Federal de Alagoas, Universidade Federal de Alagoas, Maceió, 2003.

BANDEIRA, J. M. et al. Dados abertos conectados. In: FEITOSA, D.; BITTENCOURT, I. I.; ÁVILA, T. (Orgs.). Dados abertos conectados. Maceió: Edufal, 2014. p. 1-28.

BARDIN, L. Análise de conteúdo. Lisboa: Edições 70,1977.

BRASIL. Controladoria Geral da União. Secretaria de Prevenção da Corrupção e Informações Estratégicas. Manual da lei de acesso à informação para estados e municípios. Brasília, DF: CGU, 2013. Disponível em: <http://bit.ly/1ml4vnp>. Acesso em: 13 ago. 2016.

Governo Federal. Acesso à informação: principais aspectos. [201-?]. Disponível em: <https://goo. gl/wx8sQT>. Acesso em: 27 jun. 2017.

- Ministério do Planejamento, Orçamento e Gestão. Secretaria de Logística e Tecnologia da Informação. Cartilha técnica para publicação de dados abertos no Brasil. 2012. Disponível em: $<$ https://goo.gl/2NhfqK >. Acesso em: 27 jun. 2017.

Presidência da República. Casa Civil. Subchefia para Assuntos Jurídicos. Decreto $\mathrm{n}^{\circ}$ 8.777, de 11 de maio de 2016. Institui a Política de dados abertos do poder Executivo Federal. Diário Oficial da União, Brasília, DF, 12 maio 2016. Disponível em: <http://bit.ly/2pqCq3O>. Acesso em: 7 out. 2016.

CAMARGO, B. V.; JUSTO, A. M. Iramuteq: um software gratuito para análise de dados textuais. Temas em Psicologia, Ribeirão Preto, v. 21, n. 2, p. 513-518, 2013. Disponível em: <http://bit.ly/2qk4x1Y>. Acesso em: 27 abr. 2017.

CGU - CONTROLADORIA-GERAL DA UNIÃO. Acesso à informação pública: uma introdução à Lei no 12.527, de 18 de novembro de 2011. Brasília, DF: CGU, 2011.

DUTRA, C. C.; LOPES, K. M. G. Dados abertos: uma forma inovadora de transparência. Brasília, DF, 2013. Disponível em: <http://bit.ly/2qk9HLq>. Acesso em: 20 abr. 2016.

HINE, C. Virtual ethnography. London: Sage, 2000. Disponível em: $<$ http://bit.ly/2oQGFSY>. Acesso em: 21 abr. 2016.

LIRA, M. A. B. Uma abordagem para enriquecimento semântico de metadados para publicação de dados abertos. 84 f. 2014. Dissertação (Mestrado em Ciência da Computação) - Universidade Federal 
de Pernambuco, Centro de Informática, Recife, 2014. Disponível em: <http://bit.ly/2pmpv0Y >. Acesso em: 27 abr. 2017.

MARCHAND, P.; RATINAUD, P. L'analyse de similitude appliqueé aux corpus textueles: les primaires socialistes pour l'election présidentielle française (septembre-octobre 2011). In: JOURNEES INTERNATIONALES D’ANALYSE STATISTIQUE DES DONNEES TEXTUELLES, 11, 2013, Liège. Atas... Liège: Université Paris-Sorbonne, 2013. Disponível em: $<$ http://bit.ly/1kUQ4i9> Acesso em: 4 abr. 2016.

MARSHALL, T. H. Cidadania e classe social. In: Cidadania, classe social e status. Rio de Janeiro: Zahar, 1967. p. 57-114.

OPEN DEFINITION. Definição de conhecimento aberto. [201?]. Disponível em: $<$ https://goo.gl/PmwTXi $>$. Acesso em: 27 jun. 2017.

PINHO, J. A. G. Investigando portais de governo eletrônico de estados no Brasil: muita tecnologia, pouca democracia. Revista de Administração Pública, Rio de Janeiro, v. 42, n. 3, p. 471-493, 2008.

RAGON, C. S. T. A contribuição do atendimento a pacientes especiais na graduação na formação do cirurgião-dentista: um estudo de representações sociais. 188 f. 2015. Dissertação (Mestrado em Saúde Coletiva) - Instituto de Estudos em Saúde Coletiva, Universidade Federal do Rio de Janeiro, Rio de Janeiro, 2015.

RAMINELLI, F. P. Do governo eletrônico ao governo aberto: a utilização dos sites de redes sociais pelo e-Gov brasileiro na definição da democracia participativa. In: ENCONTRO NACIONAL DO CONSELHO NACIONAL DE PESQUISA E PÓS-GRADUAÇÃO EM DIREITO, 13, 2014, Florianópolis. Anais... Florianópolis: Conpedi, 2014. Disponível em: <https://goo.gl/K8fYy3>. Acesso em: 27 abr. 2017.

SANTOS, M. C. et al. O olhar sobre a formação de professores das salas de recursos multifuncionais (SRMs) no município de Feira de Santana. In: ENCONTRO DO OBSERVATÓRIO NACIONAL DE EDUCAÇÃO ESPECIAL, 3, 2013, São Paulo. Anais... São Paulo: UFSCar; USP, 2013.

SAYÃO, L. F.; MARCONDES, C. H. O desafio da interoperabilidade e as novas perspectivas para as bibliotecas digitais. Transinformação, Campinas, v. 20, n. 2, p. 133-148, 2008. Disponível em: $<$ http://bit.ly/2p8slb6>. Acesso em: 27 abr. 2017.

TUZZO, S. A.; BRAGA, C. F. O metafenômeno no processo de triangulação da pesquisa qualitativa. In: CONGRESSO ÍBERO-AMERICANO EM INVESTIGAÇÃO QUALITATIVA, 5, Porto, 2016. Anais... Porto: Ciaiq, 2016. v. 3. Disponível em: <http://bit.ly/2qcymEZ>. Acesso em: 10 out. 2016.

WORLD WEB CONSORTIUM BRASIL. Manual dos dados abertos: governo. 2011. Disponível em: $<$ http://bit.ly/2pDSIN8>. Acesso em: 4 jan. 2016. 